Laboratorio de Arte,2-1989 http://dx.doi.org/10.12795/LA.1989.i02.14

\title{
UN PROYECTO ESCULTORICO FRUSTRADO PARA EL CEMENTERIO SEVILLANO DE SAN FERNANDO
}

\author{
por FRANCISCO JAVIER RODRIGUEZ BARBERAN
}

\begin{abstract}
El Cementerio sevillano de San Fernando, inaugurado en 1853, tenía pendientes obras públicas de importancia a fines del siglo XIX. Para la colocación de un monumento en su entrada se convocó, en 1897, un concurso. A él se presentaron escultores y arquitectos de Barcelona, Madrid y Sevilla. Enric Clarasó, Eduardo Rodríguez Bellver o Joaquín Bilbao, el ganador, son algunos de ellos. Desgraciadamente, la escultura nunca llegó a realizarse.
\end{abstract}

Towards the end of the 19th century, it was clanned to carry out major public works in the Cemetery of San Fernando in Seville, inaugurated in 1853. In 1897 a competition was organited to design a monument for the entrance to the cemetery. Various sculptors and architects from Barcelona, Madrid and Seville took part, among them Enric Clarasó, Eduardo Rodríguez Bellver and Joaquín Bilbao, the eventual winner. Unfortunately, the proposed sculpture was never actually executed.

«Ces symboles monumentaux de pierre, de bronze et de marbre qui remplissent nos cimitières du passé proche ont, si l'on peut dire, les pieds dans la terre!» Jean-Didier URBAIN

El Cementerio de San Fernando, cuya construcción se iniciara en el año de 1853, por iniciativa del Ayuntamiento hispalense, experimentó a lo largo de la segunda mitad del siglo XIX un proceso de consolidación. La acción combinada de las autoridades y la población sevillana otorgaron durante estos años la estabilidad necesaria a la necrópolis que, a fines de siglo, se encuentra a punto de superar cualquier vestigio de provisionalidad, para entrar en la nueva centuria como una institución firmemente asentada. No obstante, quedaban pendientes algunos problemas que ya se habían planteado de forma simultánea a la realización del proyecto de obras por Balbino Marrón y Rane- 
ro, en $1851^{1}$. La nunca erigida capilla del camposanto, las plantaciones masivas de arbolado que debían dar al mismo el aspecto de jardín, tan usual en la época, o, de forma muy especial, la resolución de la fachada del conjunto, continuaban siendo temas diferidos una y otra vez por la municipalidad, cuyas arcas mermadas no eran precisamente el mejor incentivo para la ejecución de esas obras. No obstante, un elemento al que he aludido anteriormente va a propiciar un cambio en esta situación, y va a convertirse en causa cercana para las actuaciones que tienen lugar en el cementerio durante los años que preceden a 1900.

El paralelismo que observamos entre las ciudades decimonónicas y los cementerios tiene uno de sus puntos de referencia obligados en la construcción, por parte de las clases acomodadas, de monumentos y panteones que sirvan para perpetuar su memoria. Los nuevos conceptos que se barajan en la relación entre los vivos y los difuntos aparecen perfectamente ejemplificados a través de estas obras, las cuales son reconocidas, incluso por las autoridades que ostentan la titularidad de los camposantos, como uno de los elementos básicos en el ornato de los mismos. El cementerio de Sevilla no permanece, como es lógico, al margen de todo este proceso, y así, en la década de 1890 pueden encontrarse ya espléndidos ejemplares de arquitectura y escultura funeraria en el interior del recinto. Sin embargo, las zonas comunes del cementerio aún dejaban bastante que desear en cuanto a cuidados $\mathrm{y}$, por supuesto, a magnificencia de sus fábricas. Son numerosos los informes municipales que hablan del estado indecoroso de gran parte del camposanto, y ello no podía consentirse en una obra que había nacido con la intención de eliminar la penosa imagen que los anteriores enterramientos sevillanos (el de San José, en Triana, y, sobre todo, el de san Sebastián) habían dejado en la sociedad hispalense. La cada vez mayor distancia que separaba las construcciones realizadas por «personas de distinción» o «magnates», como se denominan en documentos de la época, de la pobrísima infraestructura acometida por el Ayuntamiento en las zonas de uso común, amenazaba seriamente la idea del conjunto. De ahí, entiendo, surge la necesidad de proceder a obras de reforma diversas en el camposanto, entre la cuales debería haberse encontrado la que ahora nos va a ocupar; desgraciadamente, al no llevarse a cabo, pasó a engrosar la muy extensa galería de proyectos no realizados, que suponen un capítulo importantísimo en la historia de los cementerios contemporáneos.

El 14 de agosto de 1896, con motivo de un Cabildo celebrado por el Ayuntamiento hispalense, se debatió un informe de la Comisión de Cementerios sobre el estado del camposanto sevillano y las acciones que convenía llevar a cabo en el mismo. «La Comisión de Cementerios», dice el acta de la sesión,

1. Un amplio estudio del proyecto ha sido realizado por Francisco Javier Rodríguez Barberán en su artículo El plano del Cementerio de San Fernando de Sevilla, obra de Balbino Marrón y Ranero (pendiente de publicación). Más breve noticia puede hallarse en Suárez Garmendia, J.M., Arquitectura y urbanismo de Sevilla en el siglo XIX, Sevilla, 1986, pp. 161 y 162 passim. 
«aconsejaba a su Excelencia que acordase realizar determinadas obras en el Cementerio de San Fernando, con arreglo al proyecto presentado por el Arquitecto para establecer la debida separación entre las dependencias y el Campo-Santo ( $\mathrm{sic}$ ), consistentes en retranquear la verja de la rotonda de entrada y cerrar los huecos de comunicación con el jardín, excepto los absolutamente indispensables... Que debería colocarse en el centro de la rotonda un grupo alegórico en mármol o bronce, optando por lo primero, sobre su escalinata y su pedestal, abriéndose para ello un concurso; y que por último se sustituyera la Cruz de madera que se encuentra situada en la rotonda interior sobre escalinata de fábrica ordinaria con otra Cruz de iguales proporciones, de mármol, para que no desdijera de la multitud de lujosos panteones que existen construidos a su alrededor. El Sr. Laraña... dijo: que debía quedar expresamente consignado que al publicarse las bases del concurso se dijese que el grupo alegórico debía estar inspirado en el más puro sentimiento católico, puesto que había de elevarse en un cementerio para cristianos ortodoxos» ${ }^{2}$.

La cita, que he preferido conservar en casi toda su extensión, además de darnos la primera referencia del objeto concreto de este estudio, presenta varios puntos que conviene glosar, siquiera sea someramente. En primer lugar, aparece la ya comentada necesidad de otorgar a la entrada del cementerio su aspecto definitivo, algo que había sido perseguido desde los primeros momentos de la institución, y que sólo en los años finales del siglo parecía poder llevarse a cabo ${ }^{3}$. De importancia muy similar es la reforma de la rotonda central interior, en la cual, abandonado ya el proyecto primitivo de erigir allí la capilla, habrá de levantarse, unos años más tarde, el espléndido Cristo de Antonio Susillo. Esta obra, que se integraba perfectamente con las edificaciones de su entorno, requeriría un estudio aparte, en el cual, por razones obvias, no puedo detenerme. Empero, había de ser citada aquí, pues el esfuerzo económico que requerirá de la hacienda municipal ${ }^{4}$ bien pudiera considerarse como una de las causas que llevaron al olvido definitivo del proyecto de «grupo alegórico» para la entrada, al cual se van a dedicar las siguientes páginas.

Hasta el día 10 de Junio de 1897 no se presentan las bases del concurso para la construcción del monumento, realizadas en última instancia por el Arquitecto Municipal, D. José Sáez López. Estas recogen el término «monumento» en un amplio sentido, uniendo su concepto a los de «grupo, estatua y composición artística» ${ }^{5}$. Igualmente se insiste en el simbolismo católico de

2. Archivo Administrativo Municipal de Sevilla, Sección Cementerios, «Expediente formado para la erección de un monumento en la rotonda de entrada del Cementerio de San Fernando», Legajo 21 Inventario Febrero 1899. Expte. n. ${ }^{\circ} 1935$. Es transcripción del Acta del Cabildo correspondiente.

3. Son varios los expedientes municipales que, por estos años, se ocupan de las reformas de los accesos al camposanto. Véase, por ejemplo, uno de ellos, con planos de Fco. Aurelio Alvarez Millán, para realizar varios edificios (oficinas, casa del capellán, etc.) en esa zona (A.A.M.S., Legajo 11 Inventario Febrero 1899. Expte. n. $\left.{ }^{\circ} 657\right)$.

4. A.A.M.S., Sección Cementerios, Legajo 21 Inventario Febrero 1899. Expte. n. ${ }^{\circ} 1936$.

5. Expte. n. ${ }^{\circ} 1935$, supra cit. Es escrito de 10 de Junio de 1897. 
la obra, como condición indispensable para la aceptación de los proyectos, siempre conforme al espíritu surgido de la sesión en la cual fue abordado el tema por vez primera. Es éste un asunto de gran importancia, pues viene a recordarnos que los cementerios españoles, al contrario de lo que ocurre en otras naciones ${ }^{6}$, habían mantenido desde sus inicios estrechísimas relaciones con la Iglesia, pese a tratarse de instituciones dependientes de la municipalidad $^{7}$. Así, no es de extrañar que decisiones vinculadas al ornato de los camposantos se resolvieran, en gran parte de los casos, mediante símbolos explícitos de la presencia católica en aquéllos ${ }^{8}$. El riquísimo mundo de la iconografía fúnebre quedaba, por tanto, reducido a aquellos aspectos que contactaran más íntimamente con la religiosidad oficial, rechazando de plano cualquier otra posible lectura del fenómeno mortuorio 9 . Junto a esta limitación temática que, como más tarde veremos, determina en gran medida algunas de las «uniformidades» detectables en el concurso, aparecen otros apartados dentro de las bases: así, la posibilidad de presentar proyectos «gráficos o corpóreos», o la cantidad máxima (cincuenta mil pesetas) que podía presupuestarse para su ejecución. La publicación en el Boletín Oficial de la Provincia, el 2 de Julio de 1897, y en la Gaceta de Madrid, unos días después, de estas condiciones, significó el inicio de un concurso, como veremos más adelante, de extraordinario interés, y del cual, desgraciadamente, sólo poseemos un recuerdo documental.

Catorce son los proyectos presentados ante el Ayuntamiento, según queda constancia en el grueso expediente dedicado al tema. El corto plazo (poco más de dos meses) que medió entre la publicación de las bases y la entrega de los originales, el treinta y uno de Octubre, no fue óbice para que, no sólo escultores sevillanos, sino artistas de talla nacional, concurran al llamamiento del Cabildo hispalense. Esto permite que el concurso tenga, a priori, un cierto carácter de muestrario para las tendencias que llenan el panorama escultórico nacional de fines del XIX. La información, que podría resultar riquísima,

6. El tema del cementerio extramuros como idea ilustrada es tratado con amplitud por todos los autores que se acercan al problema. Véase, por ejemplo, Urbain, J.D., La société de conservation. Etude sémiologique des cimetières d'Occident, Paris, 1978, pp. 332 y ss. Urbain propone, en principio, la oposición del cementerio extramuros, «laico y municipal», frente a los enterramientos urbanos, bajo la indiscutible autoridad eclesial.

7. Así, por ejemplo, se manifiesta Carmen Riera (Els cementiris de Barcelona, Barcelona, 1981), cuando afirma que «(l)'sglesia s'ha sentit des dels inicis de la seva història usufructuària de la mort; per aixó, i malgrat la municipalització a partir del s. XVIII dels cementiris, i la progressiva aconfessionalitat dels Estats Moderns, el seu estigma segueix inesborrable als cementiris» (p. 19).

8. Piénsese que, como muestra, el Ayuntamiento de Málaga decidió en 1835 trasladar el «Triunfo» de la Inmaculada desde la ciudad al cementerio, como acto de refuerzo para el carácter sacro del mismo (Romero Torres, J.L., De la arquitectura funeraria al monumento civico: el mausoleo de Salvador Barroso en Malaga (1843-1845), en «Boletín de Arte», Universidad de Málaga, núms. 4 y 5, pp. 241 y 242 passim).

9. Un buen esquema para el análisis de la iconografía escultórica en los cementerios podemos verlo en Clegg, F., Problems of symbolism in cemetery monuments, «Journal of Garden History», vol. 4, number 3, 1984 . 
queda, no obstante, algo menguada, ya que los testimonios gráficos de los cuales disponemos son cortos. Así, de los proyectos presentados, sólo dos aparecen acompañados por algún tipo de ilustración (en ambos casos, sendas fotografías) con la que recomponer su imagen física; en los demás deberemos conformarnos con el acompañamiento «literario» a los mismos. Es por esto que nuestro interés deberá centrarse, antes que en los elementos estilísticos, apenas intuidos en los proyectos, en otros temas varios. En la propia nómina de autores que se dan cita en el concurso y la mentalidad de los mismos, reflejada en las memorias que completan sus trabajos, se perciben algunos aspectos de indudable atractivo, que pueden componer una pequeña aportación a la historia de la escultura española en el «fin de siglo» ${ }^{10}$.

La simple reseña detallada de todos los proyectos superaría, con mucho, los límites de este artículo; por ello, he preferido pasar sobre algunos con levedad, y dedicar mi atención a aquéllos que considero de más interés, tanto por la entidad de los autores como por su naturaleza o significado iconográfico. Igualmente, no se presentan por el mismo orden del expediente municipal, sino que he procedido a una pequeña clasificación, en virtud del origen o lugar de creación habitual de los artistas concurrentes: así, en primer lugar se comentarán los proyectos enviados por los autores no sevillanos, para pasar, posteriormente, a los de la ciudad hispalense. La presencia de artistas madrileños y barceloneses resultaba, durante los años finales del siglo, muy usual en obras emprendidas por toda la nación. La capitalidad de Madrid, aparejada a su condición de Corte y sede de las Academias, así como la tremenda pujanza económica, social y cultural de la ciudad catalana, las convertían en centro de atracción para los artistas. No es de extrañar que la publicación de concursos oficiales para la erección de edificios o diseños de conjuntos escultóricos, tan habituales en el urbanismo del XIX, atrajera a estos artistas, quienes contaban con el aval de su formación u obras reconocidas en ciudades de la talla de Madrid o Barcelona ${ }^{11}$. En el caso que nos ocupa son dos los proyectos que vienen de la capital de la nación, mientras que los artistas catalanes se encargan de presentar cuatro propuestas.

Los madrileños nada pueden aportarnos, pues carecen de memoria o información gráfica adjunta. El primero de ellos fue remitido conjuntamente por el arquitecto D. Jesús Carrasco y Encina ${ }^{12}$ y el escultor D. Joaquín Saldaña;

10. El tema de la escultura española decimonónica ha sido objeto en los últimos años de interesantes investigaciones, que coinciden con la revalorización generalizada para el arte del pasado siglo. La estatuaria fúnebre en concreto fue motivo de una ponencia en el II Congreso Español de Historia del Arte. Vid. Redondo Cantero, M.J., Aproximación a la escultura funeraria española del XIX, en «Actas del II Congreso...», Valladolid, 1978, pp. 145 a 149.

11. Véase, por ejemplo, lo comentado por Fontbona, F., y Miralles, F., Història de l'art català. Volum VII. Del Modernisme al Noucentisme. 1888-1917, Barcelona, 1985, p. 49 passim.

12. Se trata de un arquitecto vinculado con la estética neogótica. Vid. Navascues Palacio, P., Arquitectura y arquitectos madrileños del siglo XIX, Madrid, Instituto de Estudios Madrileños (CSIC), 1973, p. 311. 
el segundo, del que no se conserva tan siquiera carta de presentación (que sí existía en el anterior, al menos), aparece, según figura en la carpetilla existente en el expediente municipal, a nombre de Eduardo Rodríguez Bellver. A falta de otra información, entiendo puede tratarse del mismo escultor madrileño que cita Ossorio en su Galería biográfica..., académico activo en la segunda mitad del siglo, y que fue el encargado de llevar a cabo la talla y ornamentación del mausoleo del poeta romántico Quintana ${ }^{13}$. Frente a este corto panorama de los representantes capitalinos, los proyectos enviados desde $\mathrm{Ca}$ taluña (o Barcelona, para ser más concretos) suponen, tanto por el mayor conocimiento de los artistas concurrentes, como por la fortuna de conservarse amplia información sobre ellos, una agradable sorpresa.

No ha sido posible encontrar referencias respecto a José Balet, cuya propuesta aparece bajo el lema «Alfa» ${ }^{14}$. En la memoria del proyecto, que nos permite suponer la condición de escultor de Balet, vale la pena destacar algunos temas. Por un lado, la presencia, junto a tres grupos escultóricos que representarían la Fe, la Esperanza y la Caridad, respectivamente, de un cuarto conjunto, en igual situación jerárquica que los anteriores, denominado por el autor «Buenas Obras». Por otro, la utilización de la pirámide motivo arquitectónico principal de la obra resulta bastante llamativa, toda vez que ni la herencia ilustrada de los «arquitectos visionarios» ni el «revivalismo» egipcio habían calado hondo en el arte fúnebre hispano y, en todo caso, ya podían considerarse extintos a fines de siglo ${ }^{15}$.

Este cambio en el gusto viene bien representado por el proyecto de Carlos Carbonell, arquitecto, y el escultor Baldomero Cabré, «premiado», según aparece en la misiva adjunta a la memoria, «con medalla de $3 .^{a}$ clase en la exposición nacional de Bellas Artes de Madrid de 1892». La combinación de los motivos de la cruz y el ángel, tan habitual en los camposantos, es la elegida por ambos artistas. La falta de imagen gráfica es compensada por una breve, aunque jugosa, presentación. Esta viene a revelar el ya indicado «giro» en el gusto artístico, que bien pudiera corresponderse con un cambio generalizado en las costumbres de la nación, bien tratarse, en este caso, de una «adaptación interesada» a las condiciones del concurso; sólo bajo este doble prisma podrían entenderse los comentarios que en el escrito aparecen dirigidos contra las fórmulas clásicas o neo-egipcias, que consideran como contrarias a la tradición cristiana ${ }^{16}$.

13. Ossorio y Bernard, M., Galería biográfica de artistas españoles del siglo XIX, Madrid, 1883-1884, p. 589 passim.

14. A partir de ahora, y por tratarse de documentación contenida en un mismo expediente municipal (vid. nota.$^{\circ}$ ), omitiré toda referencia a pie de página en él, con el fin de evitar una multiplicación de notas que entiendo innecesaria.

15. Incluso en una sociedad como la catalana, donde la moda «neo-egipcia» había dado algunos frutos notables, el cambio de centuria se hace notar. Véase, a este respecto, la opinión de Mireia Freixa en su artículo La escultura funeraria en el Modernismo catalán, «Fragmentos», n. ${ }^{\circ} 3,1985$, pp. 51 y 52. 
Sin llegar a esta aparente radicalidad, todo lo anterior (nueva temática, cambios estilísticos) cristaliza en el monumento cuyo boceto es enviado a Sevilla por el escultor Pedro Carbonell ${ }^{17}$ y el arquitecto Fernando Mosén. A través de la fotografía que de él conservamos (Lámina I), podemos observar que se trata de un bellísimo templete o edículo neogótico («linterna funeraria» es denominado por los autores), con una serie de figuras en su interior, reconocibles como ángeles. La obra, proyectada para ser construida toda ella en piedra, se hace eco de las novedades que, con el final del siglo, irrumpen en el arte catalán. El tratamiento del conjunto (apreciable, de forma parcial tan sólo, a través de la fotografía), con la integración de elementos figurativos y arquitectónicos, la carnosidad que se ha dado a las formas vegetales que decoran el edificio (cardinas bulbosas, etc.), o la libertad general con que los motivos góticos son reinterpretados ${ }^{18}$, nos sitúan a una distancia no muy lejana de lo que la obra de artistas como Doménech y Montaner o el propio Gaudí, pasados los años, conseguirá.

Pese al nivel de las propuestas anteriores, el capítulo de la participación catalana he preferido cerrarlo con una obra que entiendo representativa de la buena aceptación que el concurso sevillano tuvo; me refiero a la pieza que el escultor catalán Enrique Clarasó envió desde la Ciudad Condal, y que tituló con el lema «Eternidad». Es Clarasó uno de los más importantes artistas catalanes en la generación última del siglo, no sólo por la calidad intrínseca de su producción, sino también por las relaciones que mantiene con figuras de la talla de Ramón Casas o Rusiñol, avanzados en la renovación pre-Modernis$\operatorname{ta}^{19}$. Cuando tiene lugar la convocatoria del Cabildo hispalense, Clarasó goza de un enorme prestigio y sus obras se multiplican, más allá incluso del ámbito catalán. Así se aprecia a través de una interesante «nota» que acompaña a la memoria enviada a Sevilla, y en la cual aparecen trabajos diversos realizados por el artista o en trance de ejecución: se mencionan piezas en el «Teatro de Variedades», el «Café Lion 'or» o el Cementerio de Montjuich, en Barcelona, un grupo para el Palacio de Justicia, en Pamplona, o el monumento de Sebastián Vidal, en Manila. La presencia dentro de ellas de la estatuaria fúnebre demuestra que el interés de Clarasó por el tema no es novedoso, e incluso su producción posterior confirma una cierta especialización en él ${ }^{20}$. De

16. Dicen los autores que «(desecharon) por completo ciertos simbolismos muy usados en los cementerios y en pugna con nuestra religión: nada de obeliscos, pirámides, columnas truncadas, urnas cinerarias, relojes de arena, etc. La cruz ha de ser el elemento primordial de un monumento funerario católico».

17. Carbonell es autor, entre otras, de la estatua de Luis Vives, existente en la Biblioteca Nacional. Véase Gaya Nuño, José A., Arte del siglo XIX, vol. XIX de «Ars Hispaniae», Madrid, 1966, p. 310. También recogido por Fontbona, F. y Miralles, F., op. cit., p. 49.

18. A este respecto, no conviene olvidar que Mireia Freixa (op. cit., p. 49) cita a Carbonell como escultor «(especializado) en ornamentación..., que posiblemente trabaj(e) de forma industrial». La entrada de la producción seriada en el arte funerario, tema de capital importancia que aquí sólo dejo apuntado, ya puede observarse en algunas de estas obras, cercanas a la frontera del siglo.

19. Fontbona, F., y Miralles, F., op. cit., p. 20 passim. 
ahí que su comparecencia en el concurso merezca, a priori, una especial atención. Poseemos también una fotografía del grupo que el escultor envió a Sevilla (Lámina II), como boceto a escala reducida de la obra propuesta. Se trata de un conjunto escultórico en mármol, cuyos temas participan de los motivos funerarios más habituales en el último tercio del XIX. Dice el escultor, en la amplia memoria unida al proyecto corpóreo, que el grupo «representa el ángel esperando el momento de dar la señal para la resurrección...; cobijándose bajo sus alas, a la derecha, la Fe, amparándose con el emblema del cristiano, la cruz; y señalando con la mano derecha el Catecismo...; a la izquierda... está la Caridad». En el pedestal, además, aparecen una urna funeraria y el «áncora» (sic), que representaría, según la citada memoria, «la esperanza que debemos tener en la inmensa bondad y gran misericordia de Dios». Como puede observarse, los temas han abandonado la referencia al mundo de lo macabro (esqueletos, imágenes del cadáver...), para introducirse de pleno en un tono religioso-didáctico, expuesto por la propia presencia de las Virtudes, elementos simbólicos como el ancla o el catecismo y, por supuesto, del ángel, auténtica constante dentro de la estatuaria fúnebre, como atestiguan el gran número de ellos presentes en los cementerios europeos de la segunda mitad del siglo ${ }^{21}$. Otros datos accesorios, como los costes del conjunto o sus propias dimensiones, que huyen de enfáticos monumentalismos ${ }^{22}$, nos dan una idea muy ajustada de cuál pudo haber sido la imagen final del proyecto, que nos descubre un tono, si se quiere, más «humano» para la escultura funeraria anterior al Modernismo.

La atención prestada a la presencia foránea en el concurso no debe apartar nuestra mirada de la participación sevillana en el mismo. En número de ocho concurren artistas hispalenses a la llamada de las autoridades, tal y como es posible colegir de las notas aparecidas en el expediente administrativo. La mayoría de ellos son artistas destacados de la ciudad, mientras que otros difícilmente pasan de ser autores de segunda fila, cuya identificación se hace complicada ante la ausencia de monografías amplias dedicadas a esta época. De ahí que haya optado en la presentación de sus proyectos, desgraciadamente desaparecidos, por componer, amén de la imagen del concurso, un pequeño «retrato generacional» de este grupo de artistas.

A la ya comentada ausencia de imágenes entre las obras presentadas se une, en algunos de los casos, la falta de documentos que compensen esta carencia. Así ocurre con el proyecto de Adolfo López Rodríguez, uno de los más im-

20. Ibídem, p. 208. Algunos ejemplos pueden verse también en el artículo ya mencionado de $\mathbf{M}$. Freixa.

21. Clegg, F., op. cit., pp. 307 a 310 passim. Aunque hace referencia tan sólo al mundo victoriano anglosajón, el libro de Edmund V. Gillon, Victorian Cemetery Art (New York, 1972), contiene un amplísimo repertorio iconográfico.

22. El coste presupuestado es de 43.000 ptas. Las medidas propuestas eran $2,70 \mathrm{~ms}$. de altura, 1,95 ms. de largo y 4,82 ms. de anchura. 
portantes escultores sevillanos del momento. Volcado hacia la escultura de carácter decorativo ${ }^{23}$, participa en las obras decimonónicas de la Catedral hispalense, sobre todo en el aparato ornamental de la Puerta de la Concepción ${ }^{24}$. De su intervención aquí, así como de las imágenes que realiza, a fines de siglo, para la sevillana iglesia de S. Andrés ${ }^{25}$, podemos deducir que la obra debió apoyarse en su amplio conocimiento de la iconografía religiosa, aunque esto no sea más que una hipótesis sin confirmación.

La situación referida para López Rodríguez se invierte en el siguiente proyecto: en él sí que poseemos una información «literaria» sobre la obra, pero carecemos, prácticamente, de noticias sobre el artista. Se trata de una arquitectura, de orden dórico, «(con) puerta simulada de bronce... (y) dos figuras rígidas (que) se amparan bajo su dintel», presentada por Luis Oñate Jiménez. Aunque su nombre no aparece citado en las fuentes contemporáneas consul$\operatorname{tadas}^{26}$, datos como la escasa presencia escultórica o la elección del dórico para el proyecto, que revela un anacronismo ciertamente significativo, me han sugerido la posibilidad de que pueda tratarse del mismo artista que firma en 1894 una pintura mural para la iglesia de Sta. María Magdalena, en la localidad sevillana de Dos Hermanas ${ }^{27}$. Al margen de la identificación, interesa especialmente la vertiente historicista del monumento, pues aunque el dórico resulta más afín a la estética romántica (e incluso prerromántica) que a la finisecular, conecta con esta última por su afán «revivalista». Esta nota caracteriza, además del proyecto de Oñate, a otros de los presentados.

Tal es el caso de la monumental propuesta de Carlos González de Eiris, escultor sevillano nacido en 1874 y especializado en temas religiosos ${ }^{28}$, el cual opta por una obra con tres cuerpos de «orden (sic) gótico», con variada iconografía sacra. De tono renacentista, por contra, es el proyecto firmado por José Ordonééz, autor, entre otras obras, de la restauración del coro y la caja de órganos de la catedral hispalense ${ }^{29}$. Se trata de un pedestal del mencionado

23. . Cascales Muñoz, José, Las Bellas Artes Plásticas en Sevilla..., Toledo, 1929, pp. 56 a 60 . Dice que, además de destacar en la escultura decorativa "(se distingui6) en los trabajos místicos o de asuntos religiosos...» (p. 56).

24. AA.VV., La Catedral de Sevilla, Sevilla, 1984, p. 312.

25. Cascales, J., op. cit., pp. 58 y 59. Menciona Cascales unas figuras de Sta. Rita, Sta. Teresa y S. Antonio de Padua, ejecutadas entre 1897 y 1898, para una capilla en cuya decoración también intervino Virgilio Mattoni. Vid. también el comentario de Guichot y Sierra (El Cicerone de Sevilla..., tomo I, Sevilla, 1925, p. 48), quien sitúa la obra de la capilla en 1893.

26. Gómez Zarzuela, Guía Oficial de Sevilla y su provincia..., Sevilla, 1897. No se menciona a Oñate entre los escultores, arquitectos, artesanos o industriales de la ciudad, y ni siquiera aparece su nombre en el habitual «Vecindario» incluido en la Guia...

27. AA.VV., Guta artística de Sevilla y su provincia, Sevilla, 1981, p. 394. El recentísimo estudio de Fausto Blazquez Sánchez, La Escultura Sevillana en la Epoca de la Exposición Iberoamericana de 1929 (1900-1930). (Avila, 1989), que contiene un amplio resumen de las fuentes utilizadas para este artículo, tampoco hace alusión a Luis Oñate.

28. Cascales, J., op. cit., pp. 65 y 66 .

29. Aunque excluido en algunos estudios de importancia sobre la escultura sevillana del XIX (véase, 
estilo sobre el que se situarían un Corazón de Jesús, un anciano representando al Tiempo, la ya habitual figura del ángel y un esqueleto. Como puede apreciarse, la heterogénea iconografía elegida, desde el clásico elemento macabro del esqueleto, hasta las figuras, más «a la moda», del Corazón de Jesús o el ángel, revelan que los nuevos temas de la imaginería mortuoria aún no se habían extendido con la amplitud que pudiera suponerse. Esto queda patente si comparamos la propuesta de Ordóñez con la de Joaquín Bilbao quien, tras la trágica muerte de Antonio Susillo, queda situado a la cabeza de los escultores sevillanos del momento ${ }^{30}$. Al margen del detalle historicista que supone la forma de enterramiento romano elegida por Bilbao para el monumento $^{31}$ y de cierto monumentalismo en sus dimensiones ${ }^{32}$, interesa resaltar que las dos figuras que debían coronar el conjunto representaban, en palabras del autor, «La $\mathrm{Fe}$ guiando un alma» ${ }^{33}$. Este apartamiento de la iconografía funeraria tradicional, sobre el cual he efectuado varios comentarios, especialmente al enjuiciar el proyecto de Clarasó, demuestra que Joaquín Bilbao, al margen del juicio crítico que pueda emitirse en torno a su obra escultórica, se encuentra conectado con la realidad artística del momento. La idea de transformar la imagen de la muerte, de «poetizar» su hasta ahora cruda estam$\mathrm{pa}$, ha triunfado en el resto de Europa ${ }^{34}$ y el concurso sevillano, con sus lógicas limitaciones y presencias heterogéneas, bien podría significar el peso específico de las nuevas propuestas en nuestra nación.

Un buen ejemplo de esta adaptación lo tenemos en el proyecto de Manuel Gutiérrez Cano, figura perteneciente a la generación de Susillo (aunque algo mayor que él), y activo aún por estos años ${ }^{35}$. A través del presupuesto por él dado, pueden obtenerse datos de interés sobre el aparato figurativo del monumento. Además de cuatro figuras «lloronas» para el pedestal y un relieve

por ejemplo, Banda y Vargas, Antonio de la, Panorámica de la escultura sevillana en el siglo XIX, en «Homenaje al prof. Dr. Hernández Díaz», Sevilla, 1982), su tarea en la ciudad fue significativa. Vid. Blázquez Sánchez, op. cit., p. 127. Entre otras obras cita «un boceto para un mausoleo».

30. Ibidem, pp. 754 y 755 . Obsérvese también la atención a él prestada por Cascales, J., op. cit., pp. 60 a 65.

31. Piénsese, por ejemplo, que para una de sus más importantes obras, el sepulcro del Cardenal Spínola, elige también un motivo fúnebre muy habitual, como es el arcosolio renacentista, con ligeras variantes. Véase AA.VV., La Catedral..., fig. 305.

32. La altura total del conjunto es de $8,70 \mathrm{~ms}$., distribuidos en $1,20 \mathrm{~ms}$. para la escalinata, $4 \mathrm{~ms}$. para el pedestal y $3,50 \mathrm{~ms}$. del grupo escultórico.

33. Cascales (op. cit., p. 62) recoge, dentro de la obra de Joaquín Bilbao, «un Grupo alegórico de la $\mathrm{Fe}$, que fue premiado en el concurso para erigir un monumento en el Cementerio de San Fernando».

34. Un comentario aparecido en La llustración artística (tomo III, año 1884, p. 362), a propósito de una «Escultura de niña», del cementerio genovés de Staglieno, bien pudiera servir de referencia para este cambio: «los escultores italianos vienen trabajando de bastante tiempo... en la empresa de poetizar la muerte... Aquel lujo de calaveras sarcásticas, aquella exhibición de cadáveres medio corrompidos... ya no priva en los cementerios de Italia».

35. Banda y Vargas, A. de la, op. cit., pp. 751 y 752 passim. Francisco Cuenca en su Museo de Pintores y Escultores andaluces contemporáneos (La Habana, 1923, p. 186), dice de él que es un «escultor adornista (sic)». 
con el tema de «La Caridad», aparecen esculturas del «Padre Eterno», la «Esperanza» y un ángel. Consideraciones técnicas aparte (el bronce, como en otros casos, es el material elegido para el grupo), interesa observar cómo un artista vinculado a la tradición romántica se integra decididamente en la nueva estética. Las palabras de Gutiérrez Cano son expresivas de todo esto: Dios se encuentra en actitud de Juez, «señalando los huesos que aparecen en el monumento», mientras que la «Esperanza» se encuentra sobre ellos «para significar que se halla como encarnada en ellos, y está mirando hacia el Angel, que llama con la trompeta a la Resurrección». Las imágenes se inclinan hacia el didactismo, con lo que el monumento se convierte, a un tiempo, en memoria y salvaguarda de la condición católica del recinto.

Muy cerca de este espíritu se encuentran los dos últimos proyectos, pertenecientes a Gustavo Luca de Tena $^{36}$ y Francisco Ceballos Montenegro, vinculado éste a las reformas que sufre la fábrica catedralicia durante la segunda mitad del siglo $\mathrm{XIX}^{37}$. El primero posee numerosos puntos de contacto con la obra de Gutiérrez Cano, pues presenta, entre otras, figuras del «Angel del Juicio Final» o la «Esperanza» ${ }^{38}$. El segundo, sin rehuir el tono aleccionador de los anteriores, introduce un mayor número de elementos simbólicos, desde un plano inclinado en su segundo cuerpo («símbolo de la inmortalidad») hasta una esfera en el último de ellos, imagen de rico simbolismo y con presencias esporádicas, pero originales, dentro del campo de lo funerario.

Aunque he preferido fijar mi atención en el análisis de las obras a concurso, no querría (ni entiendo, por otra parte, que fuera lógico) terminar estas páginas sin la reseña del resultado final del concurso, así como de la pequeña polémica suscitada por la elección del jurado.

El día 2 de noviembre de 1897, según publica el diario El Porvenir, quedó constituido el Jurado calificador. En éste, y junto a los tres miembros pertenecientes al propio Ayuntamiento ${ }^{39}$, se incluían, en número igual $\mathrm{y}$, según dice la información, «por parte de los artistas», a los pintores José Jiménez Aranda, José García Ramos y Virgilio Mattoni. El hecho de que fueran pintores los encargados de juzgar una obra arquitectónica o escultórica no deja de causar extrañeza, y así debió parecérselo a los propios jurados, pues presentaron su renuncia en los días siguientes, aduciendo este motivo. Con posterioridad (dos de Diciembre), son nombrados tres nuevos miembros: el arquitecto Juan Talavera de la Vega, Salvador Clemente, como pintor ${ }^{40}$ y Francisco Narbona, quien aparece citado como «escultor», aunque no ha sido posible obtener referencias suyas, a no ser, también como pintor ${ }^{41}$.

36. Antonio Illanes, en el discurso de ingreso a la Real Academia de BB.AA. Sta. Isabel de Hungría, titulado Antonio Susillo y su obra (publicado en «Boletín de Bellas Artes», 2. ${ }^{a}$ época, n. ${ }^{\circ}$ III. Sevilla, 1975, pp. 11 a 23), lo cita entre los escultores discípulos de Susillo.

37. AA.VV., La Catedral..., pp. 106 y 162.

38. Resulta curioso que Luca de Tena incluya una «Estatua del dolor».

39. Se trató de Alfredo Herazo, Luis Palomo y José Moreno Florido. 
La reunión definitiva de este Jurado ${ }^{42}$ tuvo lugar el dos de Abril de 1898, resultando elegido por cinco votos el proyecto de Joaquín Bilbao, contra uno de los madrileños Carrasco y Saldaña, mientras que el tercer premio se adjudicó a Gutiérrez Cano. Resulta cuando menos llamativo el resultado, casi unánime, a favor de la propuesta de Joaquín Bilbao, normal si se tiene en cuenta el prestigio del artista en la ciudad, pero que, a la vista de algunas de las presencias en el concurso (pienso, por ejemplo, en la de Enrique Clarasó), podría resultar discutible. De todas maneras esto sólo es una reflexión particular, ya que el desconocimiento de las obras no permite un juicio más acertado; igualmente, la interrupción del expediente administrativo con el acta de reunión del Jurado nos impide conocer si existió, «a posteriori», alguna polémica sobre el resultado. La ciudad, en todo caso, no resultó beneficiada por la iniciativa municipal, y la reforma de la entrada del cementerio no pudo contar, finalmente, con el monumento: las plantas ocupan hoy el lugar que en su día estuvo reservado para «La Fe guiando un alma».

40. Cuenca, F., op. cit., p. 111. Se trata de un pintor oriundo de Cádiz que, según indica Cuenca "(en) 1882 expuso un lienzo titulado La feria de pájaros en la Alfalfa de Sevilla». También es mencionado por Muro Orejón (Apuntes para la Historia de la Academia de Sevilla, Sevilla, 1961, p. 137) como autor de un boceto de cartel, propiedad de la Academia.

41. Tanto Cuenca (op. cit., pp. 267 y 268) como Muro Orejón (op. cit., pp. 109, 112 y 137) le mencionan únicamente como pintor de temas historicistas. Véase, como noticia más amplia el libro de Fernández López, J., La pintura de historia en Sevilla en el siglo XIX, Sevilla, 1981, p. 105.

42. Antes de la reunión se produjo la renuncia de Talavera de la Vega, quien fue sustituido por Mariano González Rojas. 


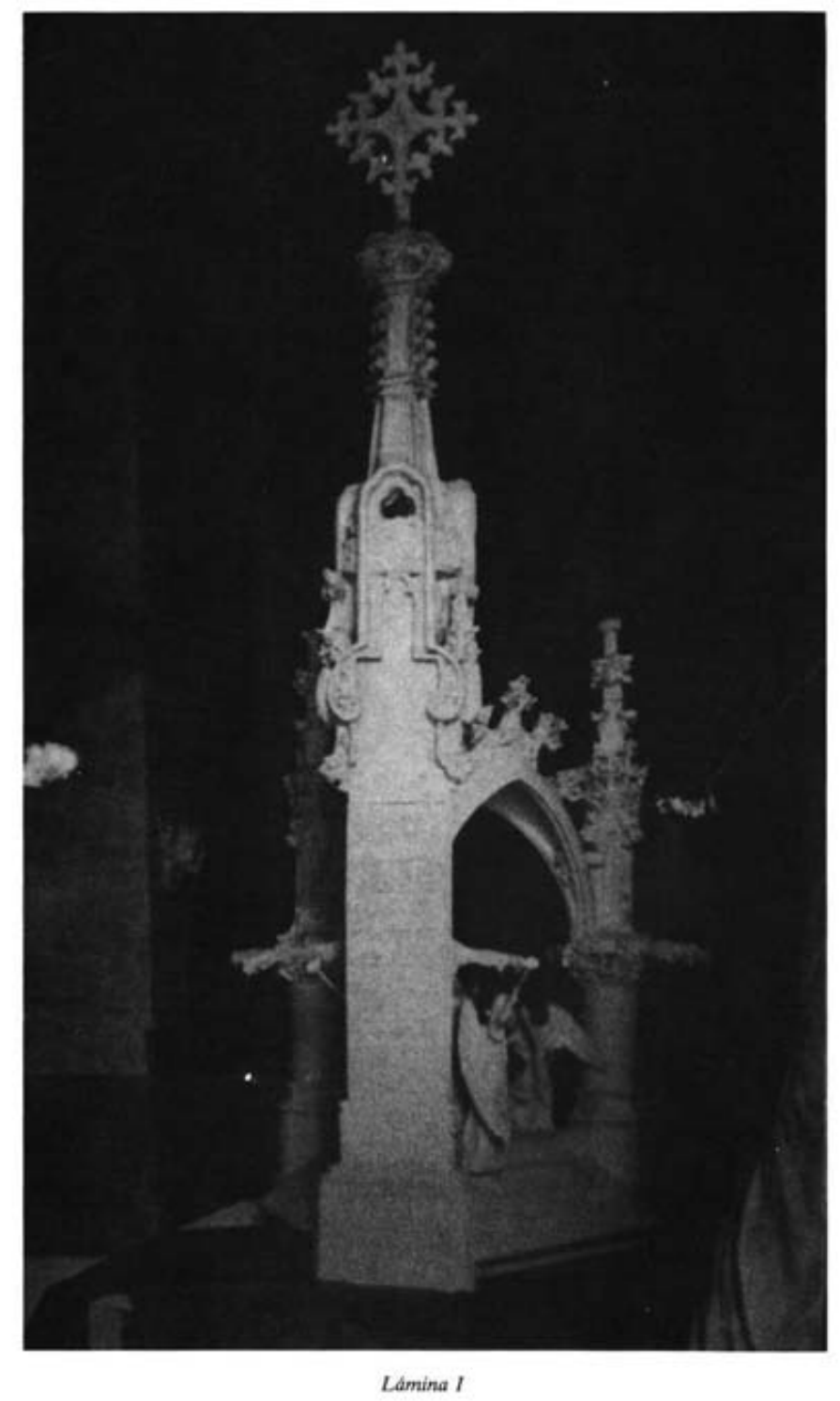




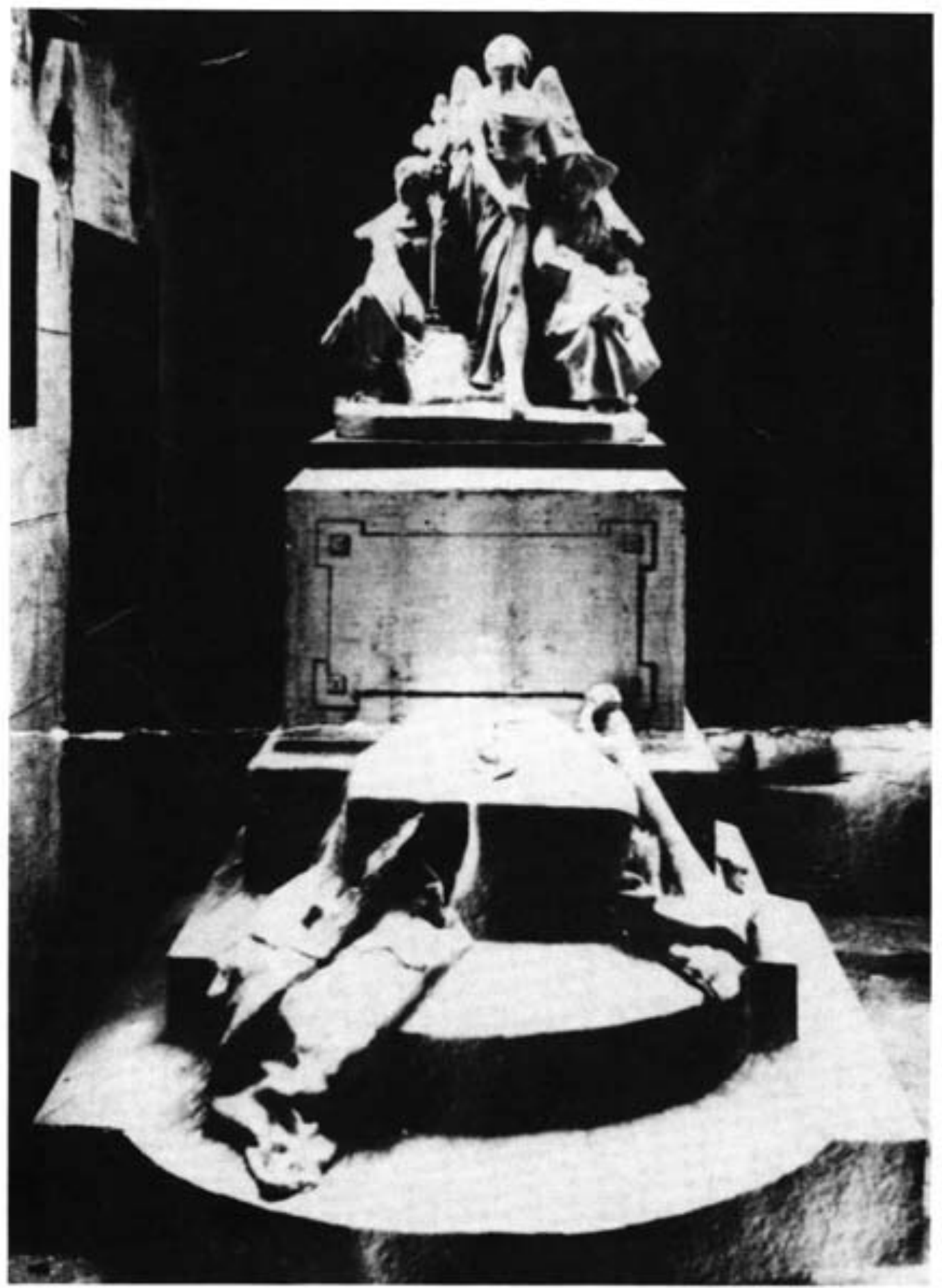

Lamina II 